\title{
Do it for the group: Developing digital competencies with Global Virtual Teams
}

\author{
Planells-Artigot, Enrique ${ }^{\text {a }}$ Ortigosa-Blanch, Arturo ${ }^{b}$ \\ ${ }^{a}$ ESIC Business \& Marketing School, Av. Blasco Ibáñez, 55 Valencia, Spain - 46021 \\ enrique.planells@esic.edu, ${ }^{b} E S I C$ Business \& Marketing School, Av. Blasco Ibáñez, 55 Valencia, \\ Spain-46021 arturo.ortigosa@esic.edu
}

\begin{abstract}
The EU established a framework of digital competencies for citizens aimed at improving their skills in a professional environment. Bearing that in mind, this study observes the implementation of some of the competencies within an academic cross-cultural project. Through the organisation of a Global Virtual Team activity, two Higher Education Institutions, one in Spain and the other one in Belgium, carried out a monitored activity with identical learning objectives in which students had to organise a trip to the partner city. Teachers divided the students ( $n=127 ; 72$ in Spain and 55 in Belgium) in groups and each group was paired with another one in the partner institutions. The purpose was to support each other in the best manner to reach the goal of preparing the trip for their own peers following some clearcut requirements.
\end{abstract}

The activity proved to be satisfactory in several areas, demonstrating the convenience of organising Global Virtual Teams as part of the study plan of a course. Previous literature has shown the advantages of putting these activities into practice, as they also facilitate learning required skills within a professional context and allow the creation of international projects without leaving their own institution. Likewise, students in both institutions expressed their satisfaction with the results and performance through the many obstacles encountered. At the same time, this study sheds new light on the importance of monitoring carefully the progress of students and strengthening academic and personal links.

Keywords: Global Virtual Teams, digital competencies, higher education. 


\section{Introduction and Theoretical Framework}

During the spring of 2020, at the time of writing this study, Higher Education Institutions (HEI) have tested their performance and resilience due to the demands of an uncertain future. The obligation in many universities all over the world to offer online classes and exams has served to reflect on the needs and advantages of offering education in another format all of a sudden. Likewise, a multitude of companies from around the world have had to reshape their way of doing business to adjust to the unexpected circumstances. Hüther (2016) advocated for the need to prepare university students to the digital requirements of the business world, especially when it comes to B2B, to count on the right human capital. Similary, Vuorikari et at. (2016) described the digital competence framework established by the EU. It consists of 21 digital competencies for citizens grouped in five different dimension areas:

- Information and data literacy

- Communication and collaboration

- Digital content creation

- Safety problems

- $\quad$ Problem-solving

Not only do these competencies add important value to the learning outcomes of any discipline, but also prepare students for the challenges of their future work environment. Training students in business intelligence and cross-cultural awareness can bring benefits in their careers (Rehg et al. 2012).

These activities represent an alternative to mobility programmes, as students do not need to incur in additional expenses for their education, in case they cannot afford a semester abroad. At the same time, these activities can easily fit in the curricula needs of their study plans (Ubachs and Henderikx, 2018).

This paper will use the term Global Virtual Teams (GVT) to describe the project, as it includes the role of the educator in the learning process. GVT can be ascribed to the category of Virtual Exchanges (O'Dowd, 2018; Ubachs and Henderikx, 2018; PlanellsArtigot and Moll-Lopez, 2020). Virtual Exchanges is "the engagement of groups of learners in extended periods of online intercultural interaction and collaboration with partners from other cultural contexts or geographical locations as an integrated part of their educational programmes and under the guidance of educators and/or expert facilitators" (O'Dowd 2018: 5). 


\section{Methodology and data collection}

The present study was carried out between two HEI in Europe: ESIC Business \& Marketing School (Valencia campus, Spain) and Erasmushogeschool Brussel (Belgium). There was a total number of 127 undergraduate students taking part, 72 in Spain and 55 in Belgium. The students in Spain were first year university students of the degree in International Business and the Belgian students were on their second year of the degree in Office Management. Despite the different degree, the courses shared similar outcomes and academic calendar, as they were business communication courses. Both courses concentrated on the development of written and oral communication skills in a business environment, including writing reports and giving presentations. Lecturers in both institutions concentrated on two of the dimension areas described above: communication and collaboration and problem-solving.

The purpose of the activity was to organise a trip to the partner city for the whole group, fictional in the case of the students in the Spanish institution, and real in the case of the Belgian institution. The latter could not take place in the end due to the pandemic. The trip had to maintain a series of requirements, common to both institutions: the trips had to last three days, staying two nights in the partner city. Each group had to choose a date for the trip in the second semester, the budget of the trip could not exceed $€ 290.00$ per person, including flight tickets, transportation, accommodation, one meal together and one group activity. Lecturers in both institutions integrated the importance of the Sustainable Development Goals (SDGs) of the UN in the project. Thus, students were equally encouraged to think about ways of making the trip sustainable and meet at least one SDG into their project and provide evidence of the results it would carry along. The teachers of each course divided the groups in groups with a team leader responsible for acting as a speaker with the lecturer, and each group was assigned a partner group in the partner institution with which it would contact in writing and by videoconference.

Communication and problem-solving were the two relevant dimension areas to tackle the project. The activity let students work on the first one from a twofold perspective: first, at an international level by encouraging team leaders of the groups to exchange emails and videoconferencing. Students quickly resorted to other software they were more familiar with to speed up responses. At the same time, students came across some inter- and intracross-cultural issues to overcome. Secondly, each group had to present their own project before their peers in the most attractive form, as the rest of classmates would vote for the best class project.

As for problem-solving, groups faced several problems they had to surmount to successfully carry out the activity: they had to contact peer groups in another country, describe the type of trip they wished, become familiar with an unknown city and find the 
main highlights which would satisfy all their classmates facing several constraints. Those constraints were given by time, budget, different cultures and events.

Peer groups would act as contacts to provide first-hand information on how best to fulfil the goals of the activity. This became one of the major obstacles in the activity, as the groups were not evenly divided. Whereas there were 14 groups for 72 students in Spain, all coordinated by one single lecturer, there were 5 groups for 55 students in Belgium, each coordinated by a different tutor. Hence, each group in Brussels had to be partnered with 2-3 groups in Valencia. This unbalance resulted in complaints from some students because of the scarce information they were receiving from their partners. As soon as one group received information from their foreign peers, they found little interest in providing additional information to the other partner teams.

There were other differences in the structure of the activity. The project in Spain carried a value of $25 \%$ of the final mark in Spain, compared to a $50 \%$ in the case of Belgium. Students in Spain were first year students in their first semester at university, compared to the students in Belgium being second year students at university. Working on the project took several weeks of the semester in both institutions, as it was first introduced in early October and the final presentation was in the first week of December. During that period, there were several in-class development sessions, in which students could work on the project, but there was also a lapse of two weeks in November when other course-related projects were integrated in the course.

At the end of the activity, each group had to give a presentation to their classmates on their organised trip. Their peers would then choose the best team in terms of development of activities and how they fit the set goals. The winning group would receive one additional point to their final mark. Additionally, students would secretly assess the effort and contribution of the other group members, so their mark would differ among them. Only the lecturer would know their secret assessment apart from them.

Students in both institutions had to answer two anonymous questionnaires both before and after the activity, identical for both institutions. There they found statements related to the learning outcomes of the course and how important they were for them. The same statements were given in the final questionnaire to compare the difference in views, and assessing results, as described in Taras et al. (2013). The final questionnaire, however, included space to let students add qualitative information about their opinion on the activity and its learning value. 


\section{Findings}

The questionnaires sent to the students before and after the activity included multiple choice questions, adding some qualitative questions in the post-activity questionnaire to gauge the students"opinions. The forms evaluated anonymously the physical characteristics of the respondents (origin, gender) together with the importance each one assigned to the activities and their level of satisfaction with the obtained results.

The questionnaires included questions for the students to assess the importance of the learning outcomes (LO), including five levels of satisfaction or agreement with several statements (Table 1), five corresponded to the highest level of satisfaction or agreement and one corresponded to the lowest level.

Table 1. Usefulness of the learning outcomes

\begin{tabular}{|l|l|l|}
\hline $\begin{array}{l}\text { How useful ARE/WERE the } \\
\text { following learning outcomes (LO)? }\end{array}$ & $\begin{array}{l}\text { Highest value } \\
\text { BEFORE }\end{array}$ & Highest value - AFTER \\
\hline LO1. Taking the minutes in a meeting. & 5-Very useful (42\%) & 4-Somewhat useful (40\%) \\
\hline $\begin{array}{l}\text { LO2. Identifying the different points } \\
\text { in favour and against in any given } \\
\text { situation in order to adopt a position. }\end{array}$ & 5-Very useful (47\%) & 4-Somewhat useful (42\%) \\
\hline $\begin{array}{l}\text { LO3. Being aware of cultural } \\
\text { differences. }\end{array}$ & 5-Very useful (56\%) & 5-Very useful (41\%) \\
\hline $\begin{array}{l}\text { LO4. Being aware of language } \\
\text { differences }\end{array}$ & 5-Very useful (52\%) & 5-Very useful (40\%) \\
\hline $\begin{array}{l}\text { LO5. Analysing situations in order to } \\
\text { negotiate successfully. }\end{array}$ & 5-Very useful (62\%) & 4-Somewhat useful (36\%) \\
\hline $\begin{array}{l}\text { LO6. Coordination among members } \\
\text { and peers. }\end{array}$ & 5-Very useful (54\%) & 5-Very useful (31\%) \\
\hline $\begin{array}{l}\text { LO7. Maintaining stereotypes and } \\
\text { prejudices among members and peers. }\end{array}$ & 1-Completely useless (29\%) & 3-Neutral (48\%) \\
\hline
\end{tabular}

Table 1 offers changes of attitude in some of the questions after the project. Students were introduced to minute-taking in their meetings for the first time, which proved to be a challenge for some, given that they could not see the relevance of recording in writing the content of a meeting. LO1 shows how some found it less valuable than they thought at the beginning, probably because it was not one of the major goals of the project. LO5 was 
equally a less important objective for the students and they ranked it differently at the end of the project.

It is worth noting how the cultural LO had a similar drop of value for the students. Although LO3 and LO4 were still very useful for the students, LO7 went from being completely useless to neutral. Frequent misunderstanding among partner groups and especially lack of replies to emails or videoconferences may have brought up an increase in prejudices to the partners or peers.

In general, students expressed their satisfaction with the activity (Fig. 1), but results were not as satisfactory as expected. Some positive responses highlighted the value of managing a large project: "I learnt how to manage the time and how to divide the activities in order to work all the members in the team. I like the activity" (respondent 41) or "I have learnt plenty of things as for example how to do a project with a team from another country" (respondent 27), whereas some negative answers showed vast problems working in the groups: "I learned that I should never ever believe in group works again and this activity could be improved by more and more strict evaluations" (respondent 62) or "I have learned that if someone is not fully interested, they won't help. We have to get the same motivation to work together or else it will not work" (respondent 82). Fig. 2 shows more optimal opinions from the students on the learning outcomes of the course, but it is hard to interpret how neutral could be considered.

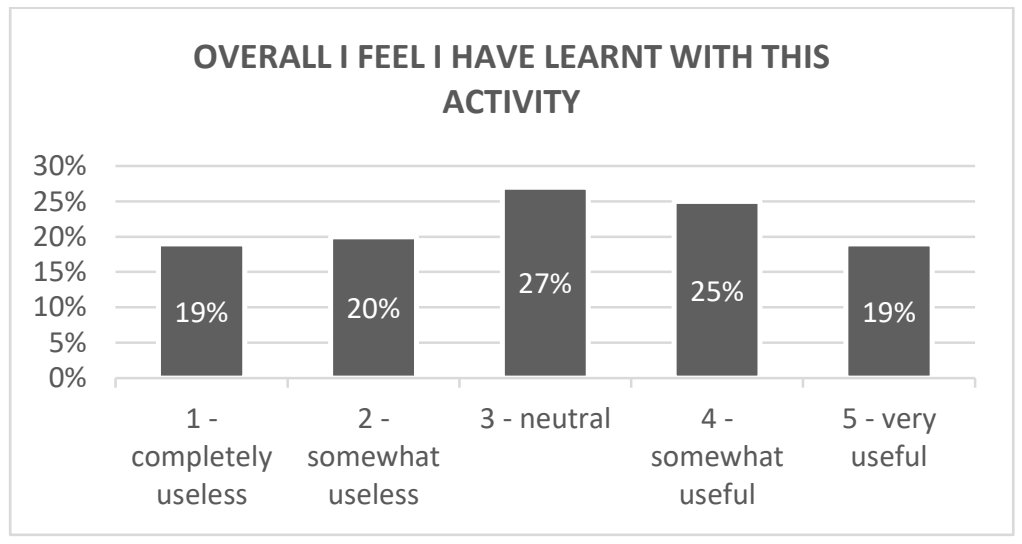

Fig. 1 Overall satisfaction with the activity 


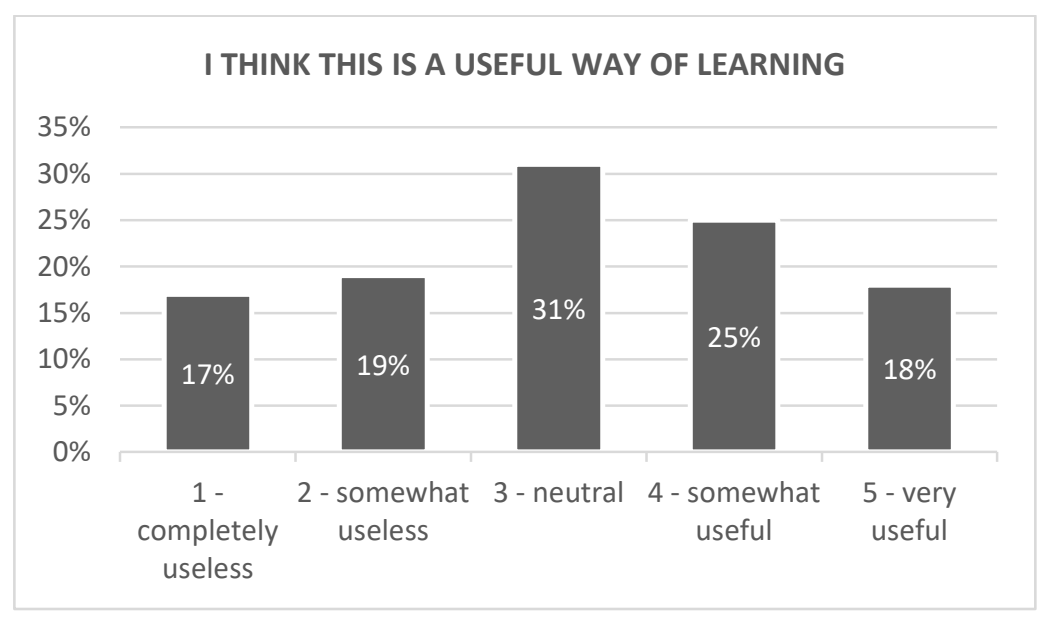

Fig. 2 Usefulness of the activity

The coordinators in both institutions expressed the overall satisfaction with the results. The coordinator in Belgium noted "[c]ommunication was the main issue (in the beginning). They loved the idea of organizing something with other students, a partner institution, but the groups were too big. I strongly recommend doing the same kind of exercise next year but with smaller groups. I would also recommend to give details concerning the communication with the partner students (facetime/Teams/Skype? How many times/minutes/...? What questions need to be answered, etc.)" (Galle, Erasmushogeschool Brussel, personal communication).

\section{Conclusions}

Previous research on GVT (Planells-Artigot and Moll-Lopez, 2020) demonstrated the satisfactory results for both students and lecturers in very remote cultures. This research has concluded that there are many intervening factors in the success of GVT. Differences with other cultures, both geographically and culturally can be taxing, although satisfactory when it comes to assessing the results. This current study, however, presented other difficulties based on lack of collaboration among members and peers. Thus, future projects should aim at clarifying the importance of close interaction, continuous collaboration and constant feedback among members in order to bring a project to a more satisfying outcome. 


\subsection{Limitations and implications for future research}

To obtain more concluding results, the questionnaires of future studies will reduce the options to assess to four items, forcing students to opt for either a negative or positive answer. At the same time, further studies could include absolutely cross-cultural teams with team members from the partner institutions to fully integrate the students in fulfilling a common goal.

\section{Acknowledgements}

The authors would like to express their gratitude to the students in both institutions taking part in the project and providing valuable, constant feedback in the process. Similarly, the authors are grateful to the support of Kathleen Galle and Ellen Thielemans, lecturers at Erasmushogeschool Brussel, for their constant support and deep interest in collaborating in this study.

\section{References}

Hüther, M. (2016). Digitalisation: An engine for structural change - A challenge for economic policy. Institut der deutschen Wirtschaft Köln.

O'Dowd, R. (2018). „From telecollaboration to virtual exchange: state-of-the-art and the role of UNICollaboration in moving forward 'e. Journal of Virtual Exchange, 1, 1-23. Researchpublishing.net. https://doi.org/10.14705/rpnet.2018.jve.1

Planells-Artigot, E. and Moll-Lopez, S. (2020; forthcoming). „Distant partners: A case study of Global Virtual Teams between Spain and South Korea".

Rehg, M., Gundlach, M. and Grigorian, R. (2012). „Examining the influence of cross-cultural training on cultural intelligence and specific self-efficacy'. Cross-cultural management, 19(2), 215-232. DOI 10.1108/13527601211219892.

Taras, V., Caprar, D. V., Rottig, D., Sarala, R. M., Zakaria, N., Zhao, F., Jiménez, A., Wankel, C., Weng, S. L., Minor, M., Bryła, P., Ordeñana, X., Bode, A., Schuster, A. M., Vaiginiene, E., Froese, F. B., Bathula, H., Yajnik, N., Baldegger, R., \& Huang, V. Z. Y. (2013). „A global classroom? Evaluating the effectiveness of global virtual collaboration as a teaching tool in management education 'e Academy of Management Learning and Education, 12(3), 414-435. http://dx.doi.org/10.5465/amle.2012.0195.

Ubachs, G. and Henderikx, P. (2018). EADTU Mobility Matrix. Maastricht: (EADTU) European Association of Distance Teaching Universities. Retrieved from: https://bit.ly/2TgbT89.

Vuorikari, R., Punie, Y., Carretero, S. and Van den Brande, L. (2016). DigComp 2.0: The Digital Competence Framework for Citizens. Update Phase 1: The Conceptual Reference Model. Luxembourg Publication Office of the European Union. doi:10.2791/11517. 